\title{
Polarization Reconfigurable Square Patch Antenna for Wireless Communications
}

\author{
M.Saravanan ${ }^{1}$, M.J.S.Rangachar ${ }^{2}$ \\ ${ }^{12}$ Electronics and Communication Engineering, Hindustan Institute of Technology and Science, Chennai, India. \\ *corresponding author, E-mail: msarawins@gmail.com
}

\begin{abstract}
In this letter, a single fed polarization reconfigurable antenna is proposed. The antenna consists of a radiating patch incorporated with a diagonal-shaped slot at its center. Four $\mathrm{p}-\mathrm{i}-\mathrm{n}$ diodes are used for polarization reconfiguration. The $\mathrm{p}$ i-n diodes are placed in diagonal slot region. The proposed antenna is designed to operate in three states - linear polarization (LP), left-hand circular polarization (LHCP) and right-hand circular polarization (RHCP) by biasing corresponding $\mathrm{p}-\mathrm{i}-\mathrm{n}$ diodes. The antenna gives measured peak gain of $6.2 \mathrm{dBi}$ for LP state and $5.82 \mathrm{dBic}$ for both RHCP and LHCP states. It also achieves 3-dB axial ratio bandwidth of $5.95 \%$ for both RHCP and LHCP configurations. The antenna finds application in areas of modern wireless communication.
\end{abstract}

\section{Introduction}

Reconfigurable antenna [1] plays a major role in recent wireless communication system due to antenna orientation restriction and to enhance channel capacity and suppression of multipath interference. Therefore designing such antennas are necessary for wireless communications. In general, polarization reconfiguration is achieved by reconfiguring radiating element by means of $\mathrm{p}-\mathrm{i}-\mathrm{n}$ diodes, RF switches or by reconfiguring feed network. Lin and wong [2] demonstrated polarization reconfigurable antenna by reconfiguring feeding network through sequential excitation by means of pin diodes in the feed network. In [3], an aperture coupled polarization reconfigurable antenna is proposed which consists of controllable RF switches on a cross aperture to excite radiating element. A most common method of achieving polarization reconfiguration is by etching a slot on radiating element and reconfiguring it by means of pin diodes [4] to bridge the gap between the slots. Jun hu et al., [5] proposed a planar low-profile $2 \times 2$ polarization reconfigurable antenna array using complementary square split ring antenna element based on substrate integrated waveguide technique. P-i-n diodes are used for switching nature of polarization. Allayioti et al., [6] presented a dual-notch polarization and beam reconfigurable microstrip antenna. Yunlong Lu et al., [7] demonstrated circularly polarized integrated filtering antennas with reconfigurable polarization. The model uses $\mathrm{p}-\mathrm{i}-\mathrm{n}$ diodes inserted in the feeding network to generate +90 deg or -90 deg phase difference at feed output for polarization reconfiguration. Yogeshwari et al., [8] presented reconfigurable antenna which consists of rhombus shaped radiator incorporated with $\mathrm{p}-\mathrm{i}-\mathrm{n}$ diodes. Panahi et al., [9] demonstrated a simple reconfigurable antenna using two p-i$\mathrm{n}$ diodes. Though the antenna achieves polarization diversity with a minimum number of diodes, the axial ratio bandwidth of the antenna is far moved from the resonant frequency of the antenna. Further, the use of pin diodes in polarization reconfiguration requires additional biasing circuit and have to be carefully designed in such a way that it should not affect antenna performance characteristics. Another approach for changing polarization states is achieved by modifying the feed network by means of $\mathrm{p}$-i-n diodes, RF switches or by using varactor diodes. Lee and sung [10] demonstrated polarization reconfigurable antenna by reconfiguring feeding network by means of $\mathrm{p}$-i-n diodes in the Y-shaped feed network. H.Sun and S.Sun [11] proposed reconfigurable antenna by reconfiguring feed network to induce phase difference in the output ports. In [12] polarization reconfiguration is achieved by modifying feed network and in [13], polarization diversity is achieved by modifying feed network which gives outputs of different phases by means of v-shaped coupling strip loaded in the feed network. This technique of reconfiguring feed network to achieve polarization diversity requires additional space for feeding network and also it is highly dependent on performance characteristics. In [14], a planar polarization reconfigurable antenna with a simple switching topology is presented. A dual-mode substrate integrated waveguide (SIW) cavity is adopted for the element antenna having two input ports for reconfiguration. Recently liquid dielectric materials are widely studied for polarization reconfiguration [16]-[16]. Though these methods give linear control over polarization, it is difficult to integrate with most of the miniature devices due to its complexity in their control mechanism and requires additional space for the fluid tank.

In this paper, a compact polarization reconfigurable patch antenna operating at $2.3 \mathrm{GHz}$ band with a center frequency of $2.35 \mathrm{GHz}$ is proposed. A diagonal shaped slot is etched in the radiating patch. Four $\mathrm{p}-\mathrm{i}-\mathrm{n}$ diodes $(1.8 \mathrm{~mm} \times 1.35 \mathrm{~mm} \times$ $1.05 \mathrm{~mm}$ ) are used to operate the antenna at three states- linear 
polarization (LP), left-hand circular polarization (LHCP) and right-hand circular polarization (RHCP) by biasing corresponding $\mathrm{p}-\mathrm{i}-\mathrm{n}$ diodes. The antenna is fabricated over FR4 substrate. The antenna performance is validated using network analyzer (N9925A) and antenna radiation pattern test system.

\section{Antenna Design Considerations}

\subsection{Antenna Geometry}

Fig. 1 shows antenna model with diagonal-shaped slot incorporated in the radiating element. The antenna is fabricated on fire retardant dielectric substrate $\left(\mathrm{FR}_{4}\right)$ having a relative permittivity of $\varepsilon_{\mathrm{r}}=4.4$. In order to have low profile thickness, the substrate is chosen to have a thickness of 1.6 $\mathrm{mm}$ and overall length and width of the substrate is $50 \mathrm{~mm} \mathrm{x}$ $50 \mathrm{~mm}$. The length $\mathrm{L}$ of the patch is taken as (Pozar et al, 1995)

$$
L=\frac{c}{2 * f * \sqrt{\varepsilon_{r}}}
$$

Where $\mathrm{c}=$ Velocity of light in air $\left(3 \times 10^{8}\right) \mathrm{m} / \mathrm{s}$

$$
\begin{aligned}
& \mathrm{f}=\text { Resonant frequency } \\
& \varepsilon_{r}=\text { Relative dielectric constant (4.4) }
\end{aligned}
$$

The effective length of the patch is taken as

$$
L_{e f f}=L-\Delta L
$$

Where $\Delta L=0.412 h \frac{\left(\varepsilon_{\text {reff }}+0.3\right)\left(\frac{w}{h}+0.264\right)}{\left(\varepsilon_{\text {reff }}-0.258\right)\left(\frac{w}{h}+0.8\right)}$

From equation (1) and equation (2), the length and width of the square patch are chosen to be $28.5 \mathrm{~mm}$ which is approximately equal to half the wavelength of operating frequency. The antenna is excited by means of $50 \Omega$ SMA connector.

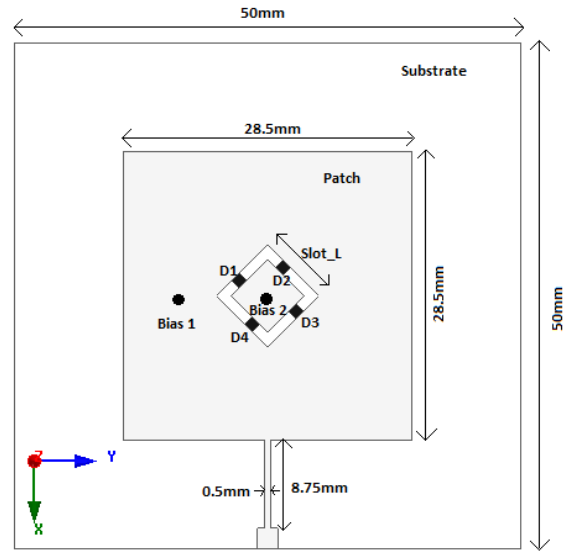

Figure 1: Geometry of proposed antenna

Four ultra-miniature p-i-n diodes (NXP BAP50-03, 50mA, $50 \mathrm{~V}$,) are placed in the diagonal slot for polarization reconfiguration. When $\mathrm{ON}$-state the diode has a series resistance and inductance of $5 \Omega$ and $1.8 \mathrm{nH}$ and when OFFstate the diode has a shunt capacitance is $0.35 \mathrm{pF}$ with the reverse resistance of $500 \mathrm{k} \Omega$. The equivalent circuit of the $\mathrm{p}$ i-n diode at ON and OFF state is shown in Fig. 2.

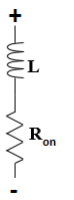

ON State

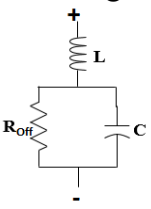

OFF State
Figure 2: Equivalent circuit model of the p-i-n diode The radiating element is etched with diagonal slot incorporated with $\mathrm{p}-\mathrm{i}-\mathrm{n}$ diodes. The width of the slot is chosen to be $1.8 \mathrm{~mm}$ based on length of the $\mathrm{p}-\mathrm{i}-\mathrm{n}$ diode used. The length of the slot is optimized with respect to operating frequency and are given in Fig. 3.
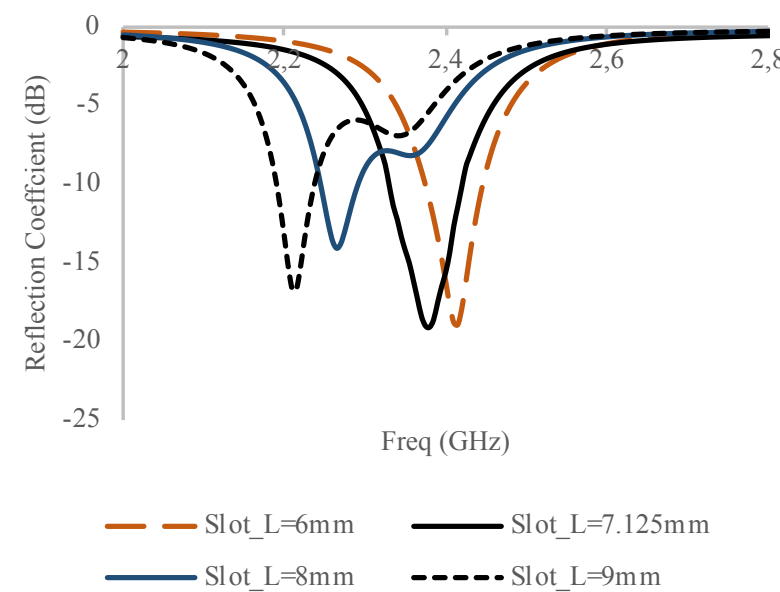

Figure 3: Variation of Reflection coefficient with respect to the slot length

It is observed that the reflection coefficient curve moves towards the lower band with an increase in slot length. This is due to the fact that, an increase in the length of slot increases the electrical length of the antenna and hence the antenna resonates at lower bands. At slot length of $7.125 \mathrm{~mm}$ which is $1 / 4$ th of patch length, the antenna resonates at operating band.

\subsection{Principle of Operation}

Table 1: Operating states of the proposed antenna

\begin{tabular}{ccccc}
\hline D1 & D2 & D3 & D4 & State \\
\hline OFF & OFF & OFF & OFF & LP \\
ON & OFF & ON & OFF & LHCP \\
OFF & ON & OFF & ON & RHCP \\
\hline
\end{tabular}

Table 1 shows a summary of antenna states. The antenna consists of four $\mathrm{p}-\mathrm{i}-\mathrm{n}$ diodes for polarization reconfiguration. Two DC bias having an excitation voltage of $4.5 \mathrm{~V}$ are used for exciting the diode switches. Bias 1 is placed in outer the slot region and bias 2 is placed in the inner region of the slot. Diodes D1 and D3 are placed in such a way that the anode of these diodes are facing towards the outer region of the slot while the cathode terminals are placed towards the inner region of the slot. Diodes D2 and D4 are placed in such a way that the cathode of these diodes are facing towards the outer region of the slot while the anode terminals are placed towards the inner region of the slot. When there is no biasing, 
all diodes are turned OFF and the antenna gives LP state as shown in Fig. 4(a). When bias 1 is applied positive potential with respect to bias 2, diodes D1 and D3 are forward biased and diodes D2 and D4 are reverse biased and the antenna is reconfigured to LHCP state as shown in Fig. 4(b). And similarly when bias 2 is applied positive potential with respect to bias 1, diodes D2 and D4 are forward biased and diodes D1 and D3 are reverse biased and the antenna is reconfigured to RHCP state as shown in Fig. 4(c).

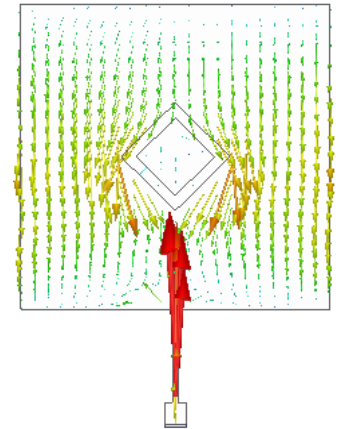

$\mathrm{t}=\mathrm{T} / 4$

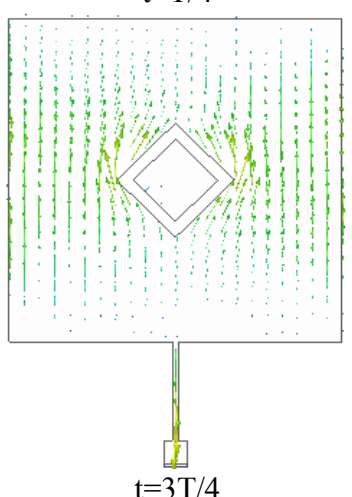

(a) LP

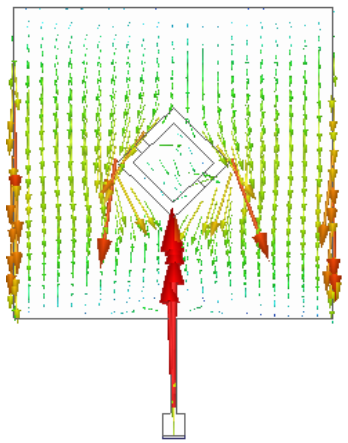

$\mathrm{t}=\mathrm{T} / 4$

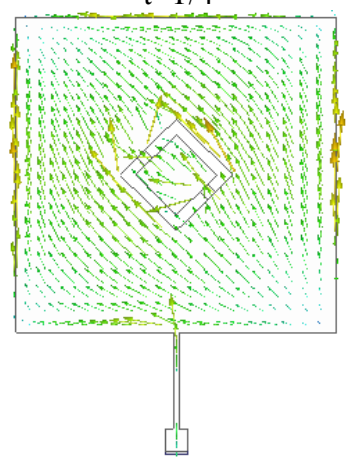

$\mathrm{t}=3 \mathrm{~T} / 4$

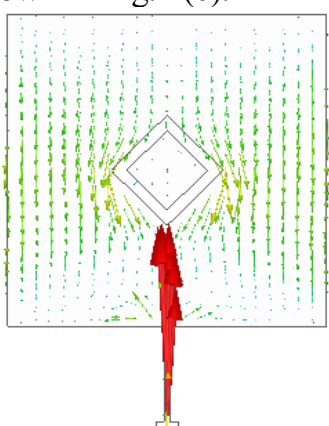

$\mathrm{t}=\mathrm{T} / 2$
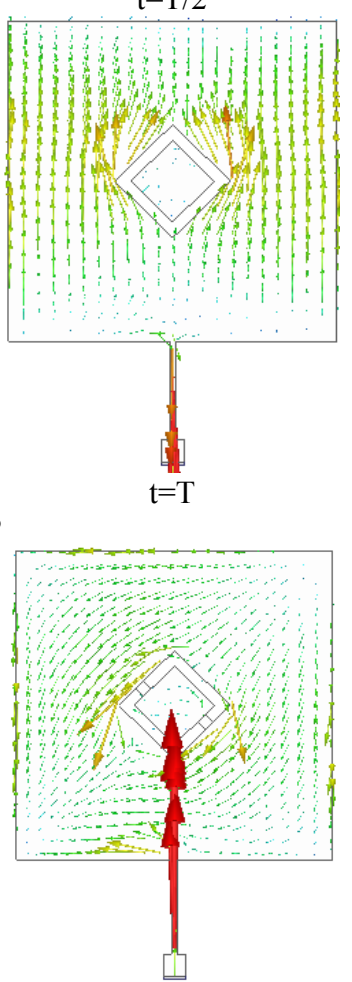

$\mathrm{t}=\mathrm{T} / 2$

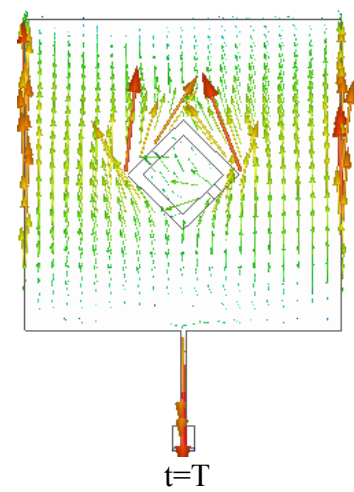

(b) LHCP

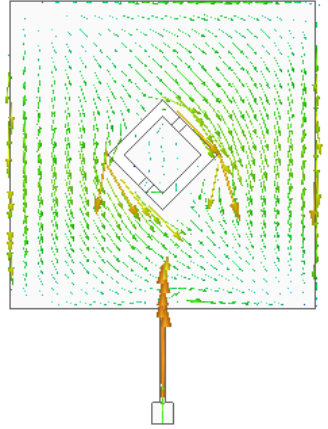

$\mathrm{t}=\mathrm{T} / 4$
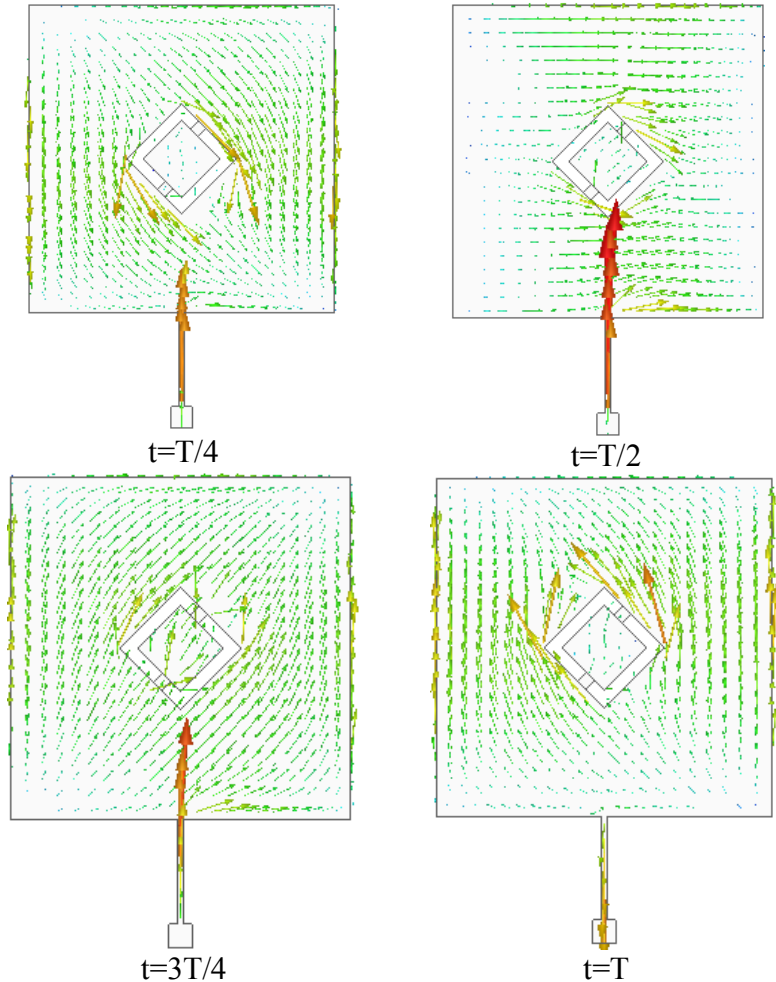

$\mathrm{t}=\mathrm{T} / 2$

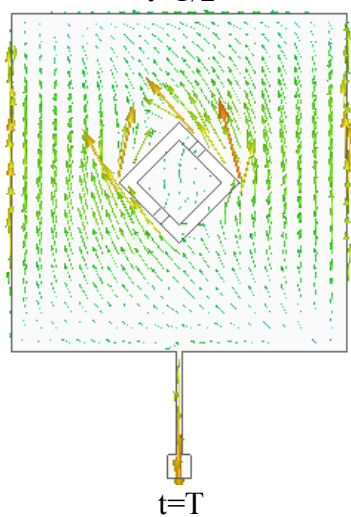

(c) RHCP

Figure 4: Current distribution on the patch at a different instance of time $\mathrm{T}$

\section{Results and Discussion}

\subsection{Impedance characteristics}

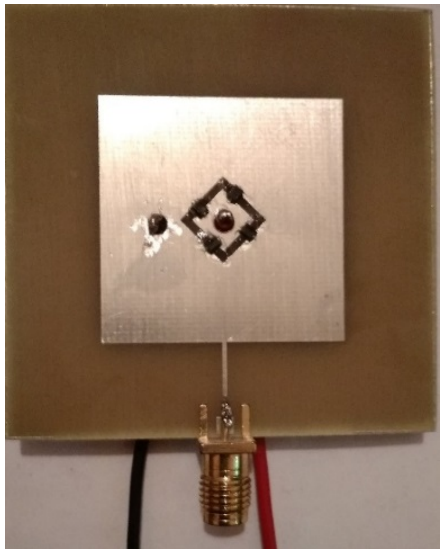

Figure 5(a): Fabricated Prototype

The prototype of the proposed antenna is fabricated on an $\mathrm{FR}_{4}$ dielectric substrate as shown in Fig. 5(a) and its impedance characteristics is measured using a network analyzer (N9925A). The measured reflection coefficient is compared and is compared with simulated results. The measured results are in good agreement with simulated results. The antenna gives measured $-10 \mathrm{~dB}$ impedance bandwidth of $4.25 \%(2.31-2.41) \mathrm{GHz}$ for both LP and CP states as shown in Fig. 5(b). 

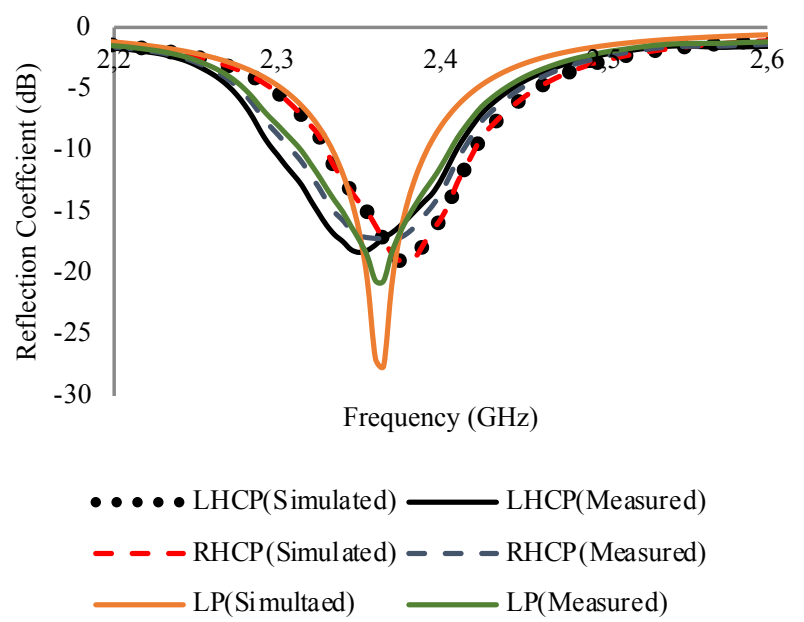

Figure 5(b): Simulated and measured reflection coefficient (dB)

\subsection{Radiation characteristics}

Fig. 6 shows simulated and measured radiation pattern corresponds to linearly polarized (LP) antenna state when all diodes are turned OFF. At this condition, the antenna reconfigures to square patch with a diagonal slot at its center. The antenna achieves symmetrical radiation pattern around zenith due to its symmetrical geometry. The antenna achieves a simulated peak gain of $6.42 \mathrm{dBi}$ and a measured peak gain of $6.2 \mathrm{dBi}$ in the direction of propagation point and crosspolarization isolation of $-19.8 \mathrm{~dB}$.

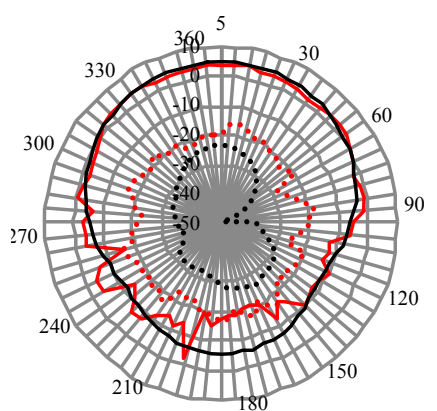

(a)

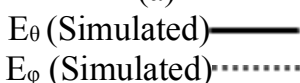

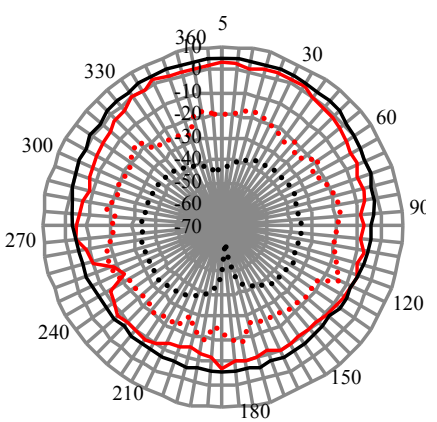

(b)
$\mathrm{E}_{\theta}$ (Measured)

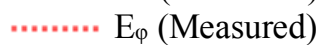

Figure 6: Simulation and Measured 2-D radiation pattern at 2.7 GHz in LP state (a) xz-plane (b) yz-plane

The measured gain is calculated using two antenna method. A standard pyramidal horn antenna having a gain of $9 \mathrm{~dB}$ is used as a reference antenna. The distance between two antennas $(\mathrm{R})$ is taken based on far-field distance $\left(\frac{2 D^{2}}{\lambda}\right)$ and the gain is calculated using Friis transmission equation given below

$$
\frac{P_{r}}{P_{t}}=\left(\frac{\lambda}{4 \pi R}\right)^{2} G_{t} G_{r}
$$
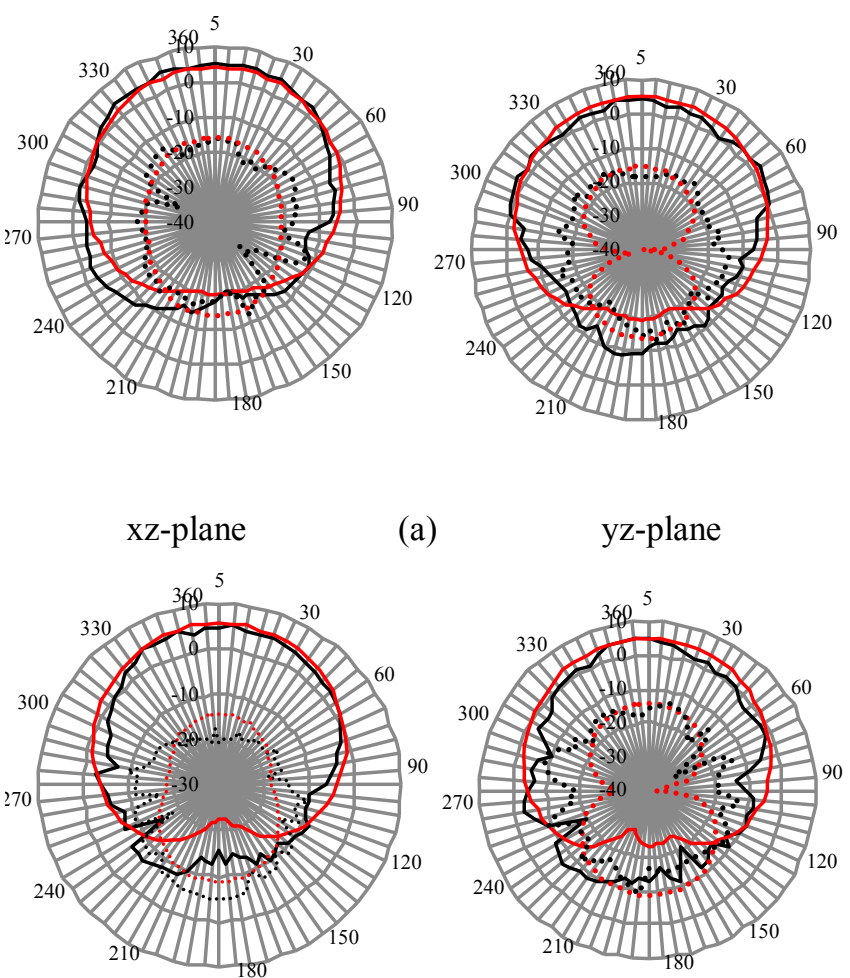

(a) yz-plane

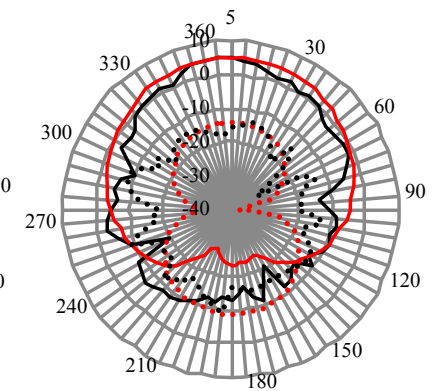

xz-plane

(b)
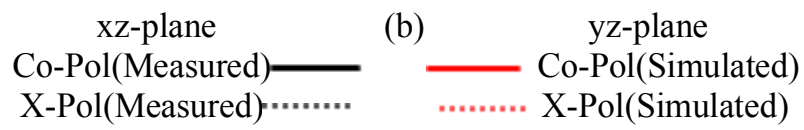

Figure 7: Simulated and measured 2-D radiation patterns at $2.37 \mathrm{GHz}$ (a) LHCP state (b) RHCP (State)

The antenna archives a measured gain of $6.2 \mathrm{dBi}$ at LP state with a peak efficiency of $71 \%$. Fig. 7 shows radiation characteristics at $\mathrm{xz}$ and $\mathrm{yz}$ plane for both LHCP and RHCP configurations. When D1 and D3 are turned ON the antenna gives radiation pattern as shown in Fig. 7(a) and When D2 and $\mathrm{D} 4$ are turned $\mathrm{ON}$ the antenna gives radiation pattern as shown in Fig. 7(b). Fig. 8 shows measured gain against operating band.

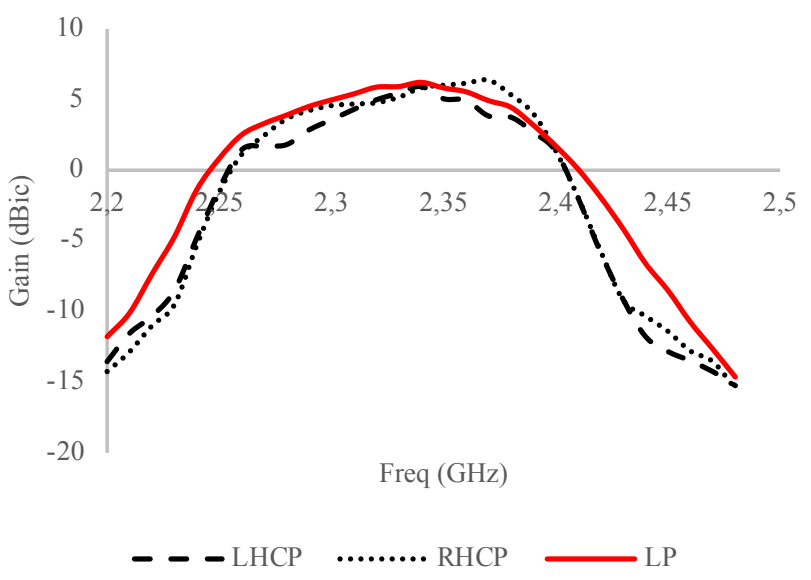

Figure 8: Measured gain across the operating band for LP and $\mathrm{CP}$ modes 
The antenna archives a measured gain of $5.82 \mathrm{dBic}$ for both LHCP and RHCP states with the efficiency of about $66 \%$ for both LHCP and RHCP states as shown in Fig. 9. The antenna achieves lesser efficiency due to use of the lossy substrate as a dielectric medium. This can be improved by using low loss substrates like roger substrates in place of $\mathrm{FR}_{4}$ substrates. The antenna achieves measured XPD of about $-20 \mathrm{~dB}$ for LP state and $-16 \mathrm{~dB}$ for $\mathrm{CP}$ state when measured at the direction of maximum radiation.

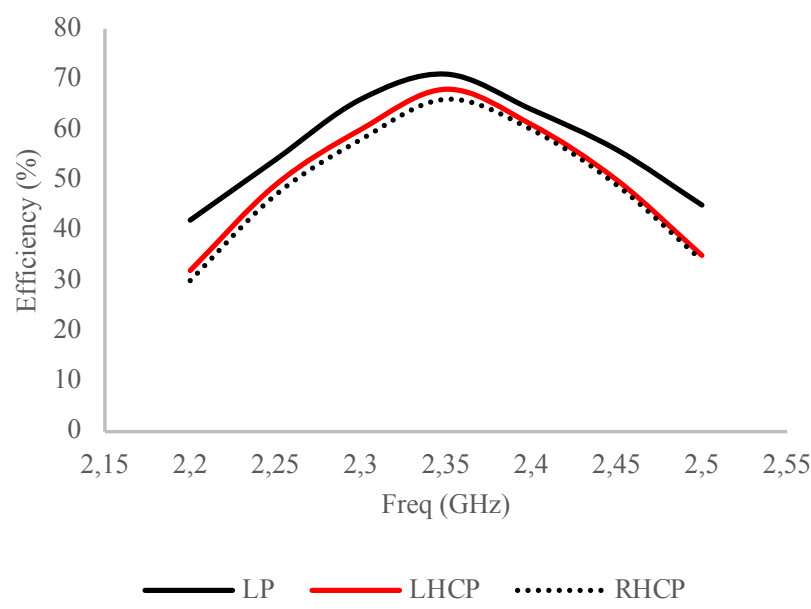

Figure 9: Measured antenna efficiency (\%)

Since the antenna operates at $\mathrm{CP}$ mode, the axial ratio bandwidth of the antenna is measured and are compared with simulated results as shown in Fig. 10. The simulated axial ratio for LHCP and RHCP are similar since the geometry of both LHCP and RHCP are identical. The antenna archives 3$\mathrm{dB}$ axial ratio bandwidth of $5.95 \%(2.3-2.44) \mathrm{GHz}$ for both LHCP and RHCP mode when measured at boresight direction of the antenna. At the resonant frequency, the amplitude and phase of orthogonal modes are equal and are in phase quadrature. However, at frequencies away from the resonant point, amplitude and phase error [17] degrades the axial ratio which limits the axial ratio bandwidth to $5.95 \%$ as shown in Fig. 10.
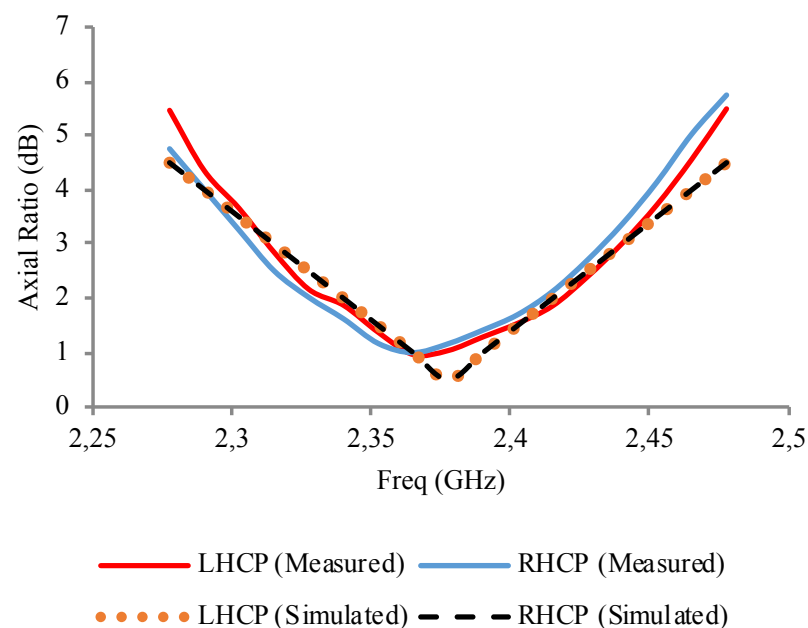

Figure 10: Variation of axial ratio $(\mathrm{dB})$ with respect to operating frequency band $(\mathrm{GHz})$
Table 2: Performance Comparison of proposed antenna

\begin{tabular}{|c|c|c|c|c|c|}
\hline $\begin{array}{l}\text { Param- } \\
\text { eter }\end{array}$ & [4] & {$[5]$} & {$[6]$} & [7] & $\begin{array}{l}\text { Propos } \\
\text {-ed } \\
\text { Model }\end{array}$ \\
\hline \multirow{3}{*}{$\begin{array}{l}\text { Size } \\
\left(\mathrm{mm}^{3}\right)\end{array}$} & $33 x$ & $50 x$ & $60 x$ & $80 x$ & $50 x$ \\
\hline & $16 x$ & $50 x$ & $60 x$ & $80 x$ & $50 x$ \\
\hline & 0.8 & 1.57 & 1.57 & 10 & 1.6 \\
\hline Switch & $\begin{array}{l}8 \text { Pin } \\
\text { diodes }\end{array}$ & $\begin{array}{l}2 \text { Pin } \\
\text { diodes }\end{array}$ & $\begin{array}{l}8 \text { Pin } \\
\text { diodes }\end{array}$ & $\begin{array}{l}4 \text { Pin } \\
\text { diodes }\end{array}$ & $\begin{array}{l}4 \text { Pin } \\
\text { diodes }\end{array}$ \\
\hline $\begin{array}{l}\text { Polariz } \\
\text {-ation }\end{array}$ & $\begin{array}{l}\text { LP, } \\
\text { LHCP, } \\
\text { RHCP }\end{array}$ & $\begin{array}{l}\text { LP, } \\
\text { LHCP, } \\
\text { RHCP }\end{array}$ & $\begin{array}{l}\text { LP, } \\
\text { LHCP, } \\
\text { RHCP }\end{array}$ & $\begin{array}{l}\text { LHCP, } \\
\text { RHCP }\end{array}$ & $\begin{array}{l}\text { LP, } \\
\text { LHCP, } \\
\text { RHCP }\end{array}$ \\
\hline $\begin{array}{l}3 \mathrm{~dB} \\
\text { AR- } \\
\text { BW }\end{array}$ & $1.6 \%$ & $2.83 \%$ & $2.57 \%$ & $\begin{array}{l}9.4 \% \\
\text { (LHCP) } \\
10.5 \% \\
\text { (RHCP) }\end{array}$ & $5.95 \%$ \\
\hline Gain & $\begin{array}{l}7.0 \mathrm{dBi} \\
(\mathrm{LP}) \\
\sim 7.3 \\
\mathrm{dBic} \\
(\mathrm{CP})\end{array}$ & $\begin{array}{l}5.95 \\
\mathrm{dBi} \\
(\mathrm{LP}), \\
6.16 \\
\mathrm{dBic} \\
(\mathrm{CP})\end{array}$ & $\begin{array}{l}7.8 \mathrm{dBi} \\
\text { (LP), } \\
\sim 7.65 \\
\mathrm{dBic} \\
(\mathrm{CP})\end{array}$ & $\begin{array}{l}6.0 \\
\mathrm{dBic}\end{array}$ & $\begin{array}{l}6.2 \mathrm{dBi} \\
(\mathrm{LP}) \\
5.82 \\
\mathrm{dBic} \\
(\mathrm{CP})\end{array}$ \\
\hline
\end{tabular}

Table 2 gives performance comparison of proposed antenna with some of the conventional antenna. It is observed that the proposed antenna is compact and achieves good 3-dB axial ratio bandwidth characteristics with a minimum number of switching elements and also achieves better gain characteristics in the operating band. Though the model in ref [7] given in table 2 has improved $3 \mathrm{~dB}$ axial ratio bandwidth for CP mode, the model consists of dual substrates which increase overall antenna profile. Furthermore, the proposed antenna designed has a single layer and the overall thickness of the antenna is about $1.6 \mathrm{~mm}$. Compared to traditional reconfigurable antennas, the proposed model uses a reduced number of switching elements for reconfiguration which eliminates the need for additional reconfigurable feed network. Hence it is very convenient to integrate with other devices when compared to traditional polarization reconfigurable antennas.

\section{Conclusion}

In this paper, a compact diagonal shaped slot circularly polarized reconfigurable antenna has been developed. The antenna has a simple structure with $p$-i-n diodes for reconfiguration rather than choosing EM bandgap structure, reconfigurable feed network. The antenna achieves better gain characteristics of $6.2 \mathrm{dBi}$ for linear polarization and $5.82 \mathrm{dBic}$ for circular polarization state with the crosspolarization isolation of $-20 \mathrm{~dB}$ for LP state and $-16 \mathrm{~dB}$ for $\mathrm{CP}$ state. The antenna also gives a wide $3-\mathrm{dB}$ axial ratio bandwidth of $5.95 \%(2.3-2.44) \mathrm{GHz}$ for both LHCP and RHCP states along the boresight direction. Hence it is better suitable for modern wireless application which prefers CP antenna characteristics.

\section{References}

[1] L.Snehalatha, Nagendra P. Pathak, Sanjeev K. Manhas, Reconfigurable Multi-Beam Dual-Band Antenna based 
on Vee Dipoles, Advanced Electromagnetics, 7(2): 1924, March 2018.

[2] W. Lin, H. Wong, Wideband Circular Polarization Reconfigurable Antenna, IEEE Trans. Antennas Propag., 63(12): 5938-5944, Dec. 2015. doi: 10.1109/TAP.2015.2489210

[3] W. Lin, H. Wong, Polarization Reconfigurable ApertureFed Patch Antenna and Array, IEEE Access, 4: 15101517, 2016. doi: 10.1109/ACCESS.2016.2552488

[4] Bharathi Anantha, Lakshminarayana Merugu, P.V.D. Somasekhar Rao, A novel single feed frequency and polarization reconfigurable microstrip patch antenna, $A E U$ - International Journal of Electronics and Communications, 72: 8-16, February 2017.

[5] J. Hu, Z. C. Hao and Z. W. Miao, Design and Implementation of a Planar Polarization-Reconfigurable Antenna, IEEE Antennas and Wireless Propagation Letters, 16:1557-1560,2017.

[6] Marion Allayioti, James R. Kelly, Raj Mittra, Beam and polarization reconfigurable microstrip antenna based on parasitics, Microwave and optical technology letters, Microw Opt Technol Lett., 60:1460-1464, 2018.

[7] Y. Lu, Y. Wang, S. Gao, C. Hua and T. Liu, Circularly polarised integrated filtering antenna with polarisation reconfigurability, IET Microwaves, Antennas \& Propagation, 11(15): 2247-2252, 2017.

[8] Yogeshwari Panneer Selvam, Lavanya Elumalai, M. Gulam Nabi Alsath, Malathi Kanagasabai, Sangeetha Subbaraj, Saffrine Kingsly, Novel Frequency- and Pattern-Reconfigurable Rhombic Patch Antenna with Switchable Polarization, IEEE Antennas Wireless Propag. Lett., 16: 1639-1642, 2017.

[9] A. Panahi, X. L. Bao, K. Yang, O. O’Conchubhair, M. J. Ammann, A Simple Polarization Reconfigurable Printed Monopole Antenna, IEEE Trans. Antennas Propag., 63(11): 5129-5134, Nov.2015.

[10] S. W. Lee, Y. J. Sung, Reconfigurable Rhombus-Shaped Patch Antenna with Y-Shaped Feed for Polarization Diversity, IEEE Antennas Wireless Propag. Lett., 14: 163-166, 2015.

[11]Hucheng Sun, Sheng Sun, A Novel Reconfigurable Feeding Network for Quad-Polarization-Agile Antenna Design, IEEE Trans. Antennas Propag., 64(1): 311-316, January 2016.

[12] S. W. Lee, Y. J. Sung, Simple PolarizationReconfigurable Antenna With T-Shaped Feed, IEEE Antennas Wireless Propag. Lett., 15: 114-117, 2016.

[13] J. S. Row, W. L. Liu, T. R. Chen, Circular Polarization and Polarization Reconfigurable Designs for Annular Slot Antennas, IEEE Trans. Antennas Propag., 60(12): 5998-6002, Dec. 2012.

[14]Zhang-Cheng Hao, Kui-Kui Fan, and Honghui Wang, A Planar Polarization-Reconfigurable Antenna, IEEE Trans. Antennas Propag., 64(4): 1624-1632, 2017.
[15] Y. H. Qian , Q. X. Chu, A Polarization-Reconfigurable Water-Loaded Microstrip Antenna, IEEE Antennas Wireless Propag. Lett., 16: 2179-2182, 2017.

[16] M. Khan, G. Hayes, S. Zhang, M. Dickey, G. Lazzi, A pressure responsive fluidic microstrip open stub resonator using a liquid metal alloy, IEEE Microw. Wireless Compon. Lett., 22(11): 577-579, Nov. 2012.

[17] D.M. Pozar and D.H Schaubert, Microstrip Antennas, the Analysis and Design of Microstrip Antennas and Arrays, IEEE Press, New York, USA, 1995. 